\title{
Xe-p9, a Xenopus Suc1/Cks protein, is essential for the Codc2-dependent phosphorylation of the anaphase- promoting complex at mitosis
}

\author{
Debabrata Patra and William G. Dunphy ${ }^{1}$ \\ Division of Biology, Howard Hughes M edical Institute, California Institute of Technology, Pasadena, California 91125 USA
}

\begin{abstract}
Degradation of mitotic cyclins on exit from M phase occurs by ubiquitin-mediated proteolysis. The ubiquitination of mitotic cyclins is regulated by the anaphase-promoting complex (APC) or cyclosome Xe-p9, the Xenopus homolog of the Sucl/C ks protein, is required for some step in mitotic cyclin destruction in Xenopus egg extracts. Specifically, if $p 9$ is removed from interphase egg extracts, these p9-depleted extracts are unable to carry out the proteolysis of cyclin B after entry into mitosis and thus remain arrested in $M$ phase. To explore the molecular basis of this defect, we depleted $p 9$ from extracts that had al ready entered M phase and thus contained an active APC. We found that ubiquitin-mediated proteolysis of cyclin B was not compromised under these circumstances, suggesting that $p 9$ is not directly required for ubiquitination or proteolysis. Further analysis of extracts from which p9 had been removed during interphase showed that, at the beginning of mitosis, these extracts are unable to carry out the hyperphosphorylation of the Codc27 component of the APC, which coincides with the initial activation of the APC. p9 can be found in a complex with a small fraction of the Cdc27 protein during M phase but not interphase. The phosphorylation of the Cdc27 protein (either associated with the APC or in an isolated, bacterially expressed form) by recombinant $\mathrm{Cdc2} /$ cyclin B is strongly enhanced by $\mathrm{p} 9$. Our results indicate that $\mathrm{p} 9$ directly regulates the phosphorylation of the APC by Cdc2/cyclin B. These studies indicate that the Suc1/Cks protein modulates substrate recognition by a cyclin-dependent kinase.
\end{abstract}

[Key Words: Xe-p9; APC; mitosis; cyclin degradation; phosphorylation; Suc1]

Received May 15, 1998; revised version accepted June 25, 1998.

The transitions of the cell cycle are controlled by the cyclin-dependent kinases (Cdks) and numerous Cdkregulatory factors (for review, see Coleman and Dunphy 1994; King et al. 1994; Morgan 1997). The Cdks consist of a catalytic subunit and a positive regulatory partner called cyclin. An important member of the C dk family is maturation-promoting factor (MPF), which contains the protein kinase Cdc2 and a B-type cyclin (Dunphy et al. 1988; Gautier et al. 1988, 1990; M urray and Kirschner 1989; M urray et al. 1989; Gautier et al. 1990; Milarski et al. 1991). At the $G_{2} / M$ transition, the action of MPF results in the phosphorylation of numerous structural and regulatory proteins that are responsible for the progression of mitosis.

A third protein component of Cdk/cyclin complexes belongs to the Sucl/C ks family of proteins. This protein has been implicated in Cdk regulation through both genetic and biochemical methods. Sucl (in fission yeast) and Cksl (in budding yeast) were both identified on the

${ }^{1}$ Corresponding author.

E-MAIL dunphy@cco.caltech.edu; FAX (626) 449-0679. basis of their ability to suppress certain temperature-sensitive mutations of Cdks (Hayles et al. 1986a,b; Brizuela et al. 1987; Hindley et al. 1987; Hadwiger et al. 1989; Moreno et al. 1989; Tang and Reed 1993; Basi and Draetta 1995). In human cells, two homologs of the Cks1 protein have been isolated (Richardson et al. 1990).

Xe-p9, the Xenopus homolog of the Sucl/C ks protein, has also been identified, and its biochemical functions have been analyzed in Xenopus egg extracts (Patra and Dunphy 1996). These studies have reveal ed that Xe-p9 (hereafter referred to simply as $\mathrm{p} 9$ ) has a role in multiple cell cycle transitions. Immunodepletion of p9 from interphase egg extracts prevents entry into mitosis, suggesting that $\mathrm{p} 9$ regulates the activation of $\mathrm{Cdc} /$ / cyclin $\mathrm{B}$ at the $\mathrm{G}_{2} / \mathrm{M}$ boundary. Because $p 9$-depleted interphase extracts can be induced to enter mitosis by addition of the recombinant Cdc2-AF mutant, which cannot serve as a substrate for the inhibitory phosphorylations on Thr-14 and Tyr-15 (Solomon et al. 1992; Kumagai and Dunphy 1995), p9 appears to be required, directly or indirectly, for the activation of C dc2 by the C dc25-catalyzed dephosphorylation of Thr-14 and Tyr-15 (Dunphy 
and Kumagai 1991; Gautier et al. 1991). Strikingly, p9depl eted extracts that have been induced to enter mi tosis by the Cdc2-AF mutant are unable to degrade mitotic cyclins. Consequently, these p9-depleted mitotic extracts are unable to re-enter interphase and the next round of the cell cycle. The ability of p9 to regulate inactivation of MPF through proteolysis of the cyclin B protein suggests that $\mathrm{p} 9$, besides binding to $\mathrm{Cdc} 2 / \mathrm{cycl}$ in $\mathrm{B}$, might also interact with other molecules.

The anaphase-promoting complex (APC) or cyclosome plays a pivotal role in the completion of mitosis (Lamb et al. 1994; Irniger et al. 1995; King et al. 1995; T ugendreich et al . 1995). The APC has been shown to be essential for the degradation of mitotic cyclins (King et al. 1995; Peters et al. 1996; Kotani et al. 1998) as well as regulators of chromosome transmission such as Pds1, Cut2, and Ase1 (Cohen-Fix et al. 1996; Funabiki et al. 1996; Juang et al. 1997). In addition, the Cdc20 and Hctl/Cdh1 family of proteins appears to regulate the APC in a substrate-specific manner (Schwab et al. 1997; Visintin et al. 1997). Destruction of mitotic cyclins occurs through ubiquitinmediated proteolysis, which includes components called E1 (the ubiquitin-activating enzyme), E2 (the ubiquitinconjugating enzyme), and E3 (the ubiquitin-ligase activity). The concerted action of these three components results in the ubiquitination of a protein and its targeting for destruction by the proteasome (for review, see Ciechanover 1994; Murray 1995; King et al. 1996; Hoyt 1997). In Xenopus, the E1 and E2 components are constitutively active, but the ubiquitin-ligase activity of E3 is activated only at $M$ phase. This activity is associated with the large, multimeric 20S complex called the APC or cyclosome (King et al. 1995; Sudakin et al. 1995). Recently, many subunits of the APC, such as BIME (APC1), RSI1 (APC 2), Cdc27 (APC3), and Cdc16 (APC6) have been identified in several organisms, thus establishing the APC as a key, evolutionarily conserved regulator of ubiquitin-mediated proteolysis (Irniger et al. 1995; King et al. 1995; Tugendreich et al. 1995; Peters et al. 1996; Yamashita et al. 1996; Zachariae et al. 1996, 1998; Kramer et al. 1998; Yu et al. 1998).

Several subunits of the APC are phosphorylated after entry into $M$ phase (King et al. 1995; Peters et al. 1996; Yamada et al. 1997). In particular, APC1-BIME and APC 3-Cdc27 undergo extensive hyperphosphorylation that results in a substantial reduction in el ectrophoretic mobility. Phosphorylation of the APC appears to be functionally important, as treatment of the APC with phosphatase abolishes its ubiquitin-ligase activity (King et al . 1995; Lahav-Baratz et al. 1995; Peters et al. 1996). In a cell-free system from clam oocytes, the inactive, interphase cyclosome can be activated by incubation with Cdc2/cyclin B, while the active mitotic form can be inactivated by treatment with an okadaic acid-sensitive phosphatase (Lahav-Baratz et al. 1995). Biochemical characterization of the A PC in Xenopus suggests that the activation of the APC may depend on multiple kinases, including Cdc2/cyclin B (King et al. 1995).

In this report, we describe our investigation of the mechanism by which the absence of $\mathrm{p} 9$ compromises the ability of mitotic extracts to degrade cyclin B. In principle, the lack of p9 could result in a failure in the activation of the APC or in some other step in APC regulation, the inability of an active APC to mediate ubiquitination of cyclin B in the absence of p9, or a defect in the degradation of polyubiquitinated cyclin B by the proteasome when $\mathrm{p} 9$ is missing. Our results indicate that the mitotic phosphorylation of the APC, which coincides closely with its activation, does not occur normally in the absence of p9. In experiments with recombinant proteins, we find that p9 strongly enhances the phosphorylation of the $\mathrm{Cdc} 27$ component of the APC by the $\mathrm{Cdc} 2$ / cyclin B complex.

\section{Results}

Depletion of p9 from extracts containing an active APC has no effect on cyclin B destruction

Previously, we reported that depletion of p9 from interphase extracts of Xenopus eggs abolished the ability of these extracts to degrade cyclin B after entry into mitosis (Patra and Dunphy 1996). In this study, we have investigated further the molecular basis of the inability of these p9-depleted extracts to carry out ubiquitin-mediated proteolysis of cyclin B. In principle, this defect could involve a failure in the activation of the APC, the inability of an active APC to mediate ubiquitination of a Cdc2-cyclin B complex lacking p9, or a defect in the recognition of ubiquitinated cyclin $B$ by the proteasome in the absence of $\mathrm{p} 9$.

To distinguish between these possibilities, we first depleted p9 from a mitotic extract in which the APC is al ready present in its active, hyperphosphorylated state (Fig. 1). For this purpose, we added an amino-terminally truncated version of cyclin Bl ( $\Delta$ cyclin B) to interphase egg extracts containing cycloheximide. Egg extracts to which $\Delta$ cyclin B has been added rapidly enter mitosis,

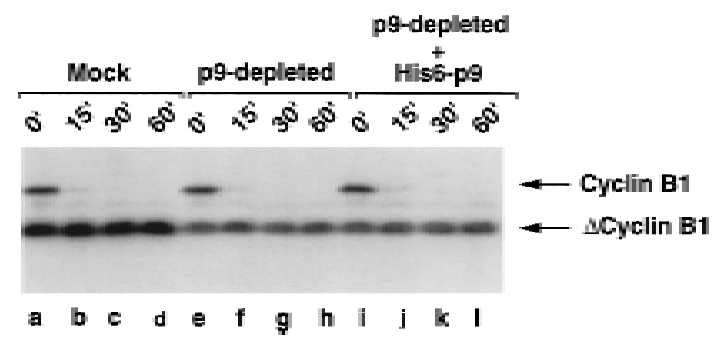

Figure 1. Depletion of $\mathrm{p} 9$ from a mitotic extract has no effect on the degradation of cyclins. Demembranated sperm nuclei were added to a cycloheximide-containing interphase extract. After nuclear assembly (50 min), $\Delta$ cyclin B (80 nM) was added to drive the extract into mitosis and arrest it at mitosis. This mitotic extract, in which cyclin degradation is activated, was then subjected to immunodepletion with anti-p9 antibodies (p9-depleted) or control rabbit anti-mouse IgG antibodies (mock). For the add-back experiment, His6-p9 $(5 \mathrm{ng} / \mu \mathrm{l})$ was added to a portion of the p9-depleted extract. A Cdc2-AF/cyclin B1 complex (10 nM ) was added to these extracts. The destruction of cyclin B1 was monitored by processing of al iquots $(2 \mu \mathrm{l})$ for immunoblotting with anti-cyclin B1 antibodies. 
but cannot exit mitosis because this truncated cyclin lacks a destruction box and thus cannot undergo ubiquitination (Glotzer et al. 1991). Importantly, however, $\Delta$ cyclin B is fully competent for activation of the cyclin destruction machinery (Glotzer et al. 1991; Luca et al. 1991).

N ext, we treated the mitotic extracts containing $\Delta c y$ clin B with either control or anti-p9 antibodies bound to protein $A$ beads. As described previously, treatment of egg extracts with anti-p9 anti bodies resulted in the quantitative removal of $p 9$. As expected, there was no reduction in the amount of p9 in mock-depleted extracts treated with control antibodies (data not shown; see Patra and Dunphy 1996). Then, we added full-length cyclin B1 (which contains a destruction box) to mock-depleted extracts, p9-depl eted extracts, or p9-depleted extracts to which recombinant His6-p9 had been restored after the immunodepletion procedure.

Weobserved that mock-depl eted mitotic extracts were able to degrade the full-length cyclin B rapidly (within 15 min), indicating that activation of the APC had occurred normally (Fig. 1, lanes a-d). Significantly, cyclin B1 destruction occurred with similar kinetics in p9-depleted extracts (Fig. 1, lanes e-h). Similar results were obtained with p9-depleted extracts containing exogenously added His6-p9 (Fig. 1, Ianes i-I). Taken together, these observations suggest that $p 9$ is not required for the recognition of $\mathrm{Cdc} 2$ /cyclin B by the APC or the proteasome, as both ubiquitination and proteolysis of cyclin B can proceed normally in p9-depleted extracts in which the APC is al ready active.

p9 is required for the hyperphosphorylation of the Cdc27 component of the APC

The activation of the APC on entry into mitosis closely correlates with the hyperphosphorylation of several of its subunits. In the case of Cdc27 (APC 3), this phosphorylation results in a substantial reduction in the mobility of Cdc27 in SDS gels (King et al. 1995; Peters et al. 1996; Y amada et al. 1997). To assess whether p9 might be required for the mitotic hyperphosphorylation of the APC, we depleted p9 from interphase extracts. As described previously, p9-depl eted extracts are unable to enter mitosis because of a failure to activate $\mathrm{Cdc} 2$ by dephosphorylation of its inhibitory Tyr-15 and Thr-14 residues (Patra and Dunphy 1996). However, p9-depleted interphase extracts can be induced to enter mitosis by the addition of the Cdc2-AF/ $\Delta$ cyclin B complex, which contains a mutant $\mathrm{Cdc} 2$ subunit that cannot undergo inhibitory phosphorylation. As described previously (Patra and Dunphy 1996), p9-depleted extracts driven into mitosis with Cdc2-AF/ $\Delta$ cycl in B cannot carry out degradation of full-length cyclin B1 (Fig. 2B, lanes f-n). In contrast, mock-depleted extracts or p9-depleted extracts containing exogenously added His6-p9 can degrade fulllength cyclin B1 when triggered to enter mitosis with Cdc2-AF/ $\Delta$ cyclin B (Fig. 2B, lanes a-e and o-s, respectively). Strikingly, when we examined the phosphorylation state of Cdc27 in these various extracts, we ob-
A

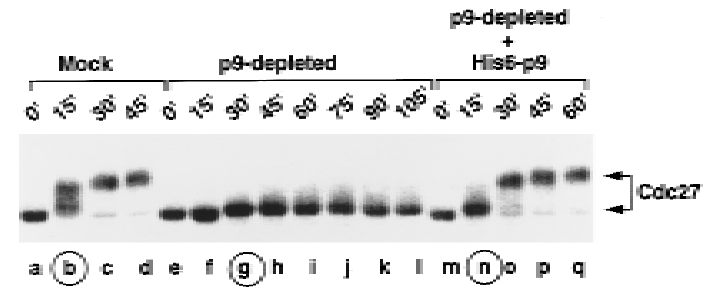

B

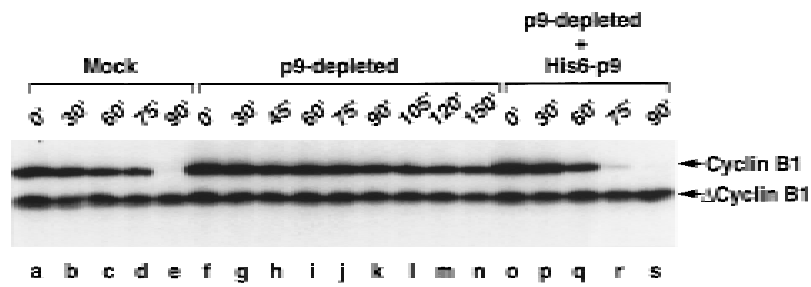

Figure 2. Lack of hyperphosphorylation of Cdc27 correlates with the inability of extracts to degrade cyclins when p9 is depleted prior to mitosis. (A) Interphase egg extracts containing cycloheximide were immunodepleted with control and anti-p9 antibodies. Demembranated sperm nuclei were added to a mock-depleted extract (lanes a-d), a p9-depleted extract (Ianes $\mathrm{e}-\mathrm{l}$ ), and a p9-depleted extract containing $5 \mathrm{ng} / \mu \mathrm{l}$ of His6-p9 (lanes $\mathrm{m}-\mathrm{q}$ ). After a 50-min incubation, a Cdc2-AF/ $\Delta$ cyclin B complex (10 nM ) was added to drive the extracts into mitosis. At the indicated times after addition of complex, aliquots $(2 \mu \mathrm{l})$ were removed for immunoblotting with anti-Cdc27 antibodies. The time at which the extracts entered mitosis is indicated by the circled letters. (B) In the same experiment as in A, after the extracts had entered mitosis, full-length human cyclin B1 was added, and its destruction was monitored by immunoblotting with antibodies against human cyclin Bl. (Lanes a-e) Mockdepleted extract; (lanes f-n), p9-depleted extract; (lanes o-s) p9depleted extract to which recombinant His6-p9 (5 ng/ $\mu \mathrm{l})$ was added.

served that the hyperphosphorylation of Cdc27 was strongly compromised in the absence of $\mathrm{p} 9$. In particular, there was only a slight retardation in the el ectrophoretic mobility of $\mathrm{Cdc} 27$ in p9-depleted extracts on induction of mitosis with Cdc2-AF/ $\Delta$ cyclin B (Fig. 2A, lanes e-l), indicating that most, but not all, of the mitotic phosphorylation of Cdc27 depends on the presence of p9. In contrast, $\mathrm{Cdc} 27$ underwent extensive phosphorylation at mitosis in either mock-depleted extracts or p9-depleted extracts containing His6-p9, as indicated by a substantial decrease in the electrophoretic mobility of $\mathrm{Cdc} 27$ in SDS gels (Fig. 2A, lanes a-d and m-q, respectively).

In addition to $\mathrm{Cdc} 27$, other regulators of mitosis not associated with the APC also undergo phosphorylation during $M$ phase. Such proteins include Cdc25 (Izumi et al. 1992; Kumagai and Dunphy 1992), Weel (Parker and Piwnica-Worms 1992; McGowan and Russell 1993; Mueller et al. 1995a; Watanabe et al. 1995), and Myt1 (Mueller et al. 1995b; Liu et al. 1997), which collectively regulate the inhibitory phosphorylation of $\mathrm{Cdc} 2$. To assess whether the phosphorylation of these components might also be compromised in the absence of p9, we 
subjected mock-depleted and p9-depleted extracts to immunoblotting with anti-Cdc25, anti-Weel, and antiM yt1 anti bodies (Fig. 3). Under conditions where the absence of p9 largely abolished mitotic hyperphosphorylation of Cdc27 (Fig. 3A), the phosphorylation of Cdc25, Weel, and Mytl did occur on entry of p9-depleted extracts into mitosis (Fig. 3B). However, the phosphorylation of these proteins, especially Cdc25 and Weel, was delayed by about 30 min relative to the phosphorylation that occurred in control extracts (Fig. 3B). In other experiments, we treated p9-depleted interphase extracts with okadaic acid, a phosphatase inhibitor that induces premature mitosis in Xenopus egg extracts and other experimental systems (Félix et al. 1990a; Jessus et al. 1991; Picard et al. 1991). Although Cdc25, Weel, and Myt1 all became phosphorylated on addition of okadaic acid, the hyperphosphorylation of Cdc27 did not occur in these p9-depleted, okadaic acid-treated extracts (data not shown). Taken together, these results indicate that p9 is

A

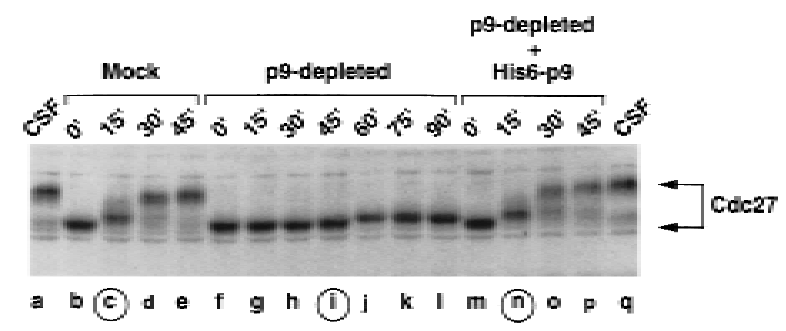

B

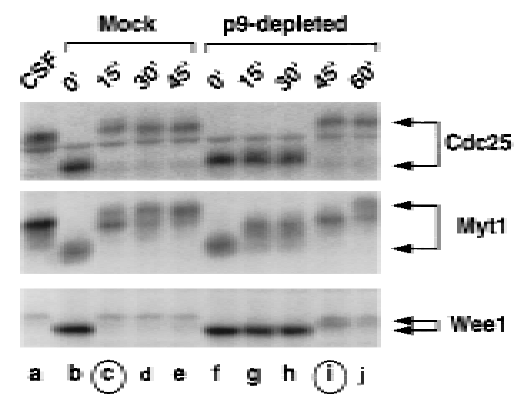

Figure 3. Comparison between the phosphorylation of $\mathrm{Cdc} 27$ versus that of $\mathrm{Cdc} 25$, Weel, and Mytl during the transition from interphase to mitosis in the absence of p9. (A) Interphase egg extracts containing cycloheximide were immunodepleted with control and anti-p9 antibodies as in Fig. 2A. At the indicated times after addition of the Cdc2-AF/ $\Delta$ cyclin B complex, aliquots $(2 \mu \mathrm{l})$ were removed for immunoblotting with antiCdc27 antibodies. The time of mitosis is indicated by the circled letters. (Lane a) $2 \mu$ of CSF extract; (lanes b-e) mockdepleted extract; (lanes f-l) p9-depleted extract; (lanes m-q) p9depleted extract containing $5 \mathrm{ng} / \mu \mathrm{l}$ of His6-p9. (B) In the same experiment as in A, the phosphorylation states of the $\mathrm{Cdc} 25$, Myt1, and Weel proteins were investigated. Aliquots $(2 \mu \mathrm{l})$ were taken at 15-min intervals and processed for immunoblotting with antibodies against the Xenopus Cdc25 (top), Myt1 (middle), and Weel (bottom). (Lane a) $2 \mu \mathrm{l}$ of CSF extract; (lanes b-e) mock-depleted extract; (lanes f-j) p9-depleted extract. required at mitosis for the phosphorylation of $\mathrm{Cdc} 27$ component of the APC but is less important for the phosphorylation of several other mitotic phosphoproteins such as Cdc25, Weel, and M yt1. Furthermore, the defect in phosphorylation of $\mathrm{Cdc} 27$ in the absence of $\mathrm{p} 9$ cannot be bypassed by the addition of phosphatase inhibitor (e.g., okadaic acid) that strongly inhibits anti-mitotic phosphatase activity.

p9 and Cdc27 can be coimmunoprecipitated during mitosis

To explore the relationship between $p 9$ and the APC in greater detail, we asked whether these components could associate physically with one another during the course of the cell cycle. For this purpose, we immunoprecipitated both interphase and $\mathrm{M}$-phase extracts with anti-p9 or control antibodies and then immunoblotted the immunoprecipitates with anti-C dc27 antibodies (Fig. 4A). We observed that the hyperphosphorylated Cdc27 present in $\mathrm{M}$-phase extracts could clearly be immunoprecipitated with anti-p9 antibodies (Fig. 4A, Iane d), whereas little, if any, of the hypophosphorylated Cdc27 in interphase extracts could be coimmunoprecipitated specifically with p9 (Fig. 4A, lane f). To pursue this observation further, we performed immunoprecipitation of $M$ phase and interphase extracts with anti-Cdc27 antibodies and then processed these immunoprecipitates for immunoblotting with anti-p9 antibodies (Fig. 4B). Consistent with the results described above, we found that p9 could be detected in the anti-C dc27 immunoprecipitates from $\mathrm{M}$-phase but not interphase egg extracts. In quantitation experiments, we estimate that $\sim 2 \%$ of the p9 and Cdc27 can be coimmunoprecipitated during $M$ phase (data not shown). By immunoblotting the antiCdc27 immunoprecipitates with antibodies against Xenopus Cdc2 and cyclin B2, we could al so detect Cdc2 and cyclin B2 in association with a complex containing $\mathrm{Cdc} 27$ during $\mathrm{M}$-phase. During interphase, neither $\mathrm{Cdc} 2$ nor cyclin B2 (which is absent in these cycloheximidecontaining interphase extracts) could be found in antiCdc27 immunoprecipitates (Fig. 4B). In conclusion, p9, Cdc2, and cyclin B2 can be found in a complex with Cdc27 during $M$ phase.

The phosphorylation of APC components by recombinant $\mathrm{Cdc} 2 /$ cyclin $\mathrm{B}$ is strongly enhanced by $\mathrm{p} 9$

In principle, the association of $\mathrm{p} 9$ with the $\mathrm{Cdc} 27$ during $M$ phase could reflect a targeting of the $\mathrm{p} 9 / \mathrm{Cdc} 2 / \mathrm{cyclin}$ $B$ complex for ubiquitination by the APC. An alternative, but not mutually exclusive, explanation is that be cause phosphorylation and activation of the APC depend on active $\mathrm{Cdc}$ / cyclin B, p9 could direct this Cdk to APC components such as $\mathrm{Cdc} 27$ to facilitate their phosphorylation. To address this notion, we tested the ability of a recombinant $\mathrm{Cdc} 2 /$ cyclin $\mathrm{B}$ complex to phosphorylate APC components in the absence and presence of p9 in vitro. For these experiments, we utilized two different 
A

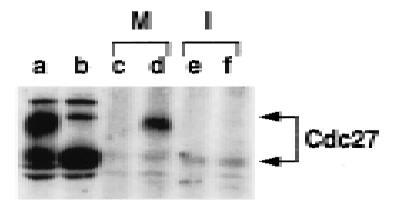

B

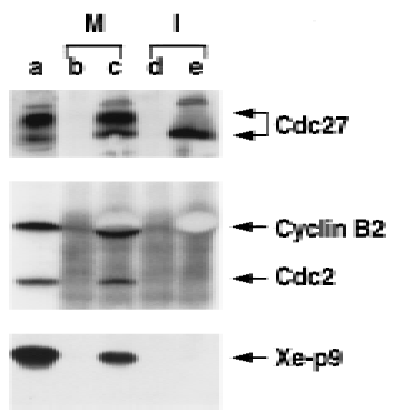

Figure 4. $C$ dc27 coimmunoprecipitates with $p 9$ during $M$ phase. (A) p9 was immunoprecipitated with anti-p9 antibodies from cycloheximide-containing CSF extracts (M) or interphase extracts (I). The antibodies $(100 \mu \mathrm{g} / \mathrm{ml})$ were recovered by use of protein A-Sepharose beads ( $100 \mu \mathrm{l}$ per $\mathrm{ml}$ of extract). The beads were washed four times with EB buffer $(80 \mathrm{mM} \beta$-glycerolphosphate, $20 \mathrm{~mm}$ EGTA, $15 \mathrm{~mm} \mathrm{M} \mathrm{gCl}_{2}$ at pH 7.3) containing $2 \mathrm{~mm}$ sodium orthovanadate and $25 \mathrm{~mm}$ sodium fluoride, followed by two washes with HBS. The beads were then subjected to SDSPAGE in a $10 \%$ polyacrylamide gel and processed for immunoblotting with anti-Cdc27 antibodies. (Lane a) $2 \mu \mathrm{l}$ of CSF extract; (lane b) $2 \mu$ of interphase extract; (lanes c, e) protein A beads containing control antibodies that were incubated in CSF and interphase extracts, respectively; (lanes $d, f$ ) protein $A$ beads containing anti-p9 antibodies that were incubated in CSF and interphase extracts, respectively. The panel depicts an immunoblot with anti-Cdc27 antibodies. (B) The experiment was repeated as in part A except that anti-C dc27 antibodies were used for the immunoprecipitation. The panels depict immunoblots with anti-Cdc27, anti-Xenopus cyclin B2, anti-Cdc2, and antip9 antibodies, as indicated. (Lane a) Two microliters of CSF extract; (lanes b, d) protein A beads containing control antibodies that were incubated in CSF and interphase extracts, respectively; (lanes C, e) protein A beads containing anti-Cdc27 antibodies that were incubated in CSF and interphase extracts, respectively.

preparations of the APC: one that had been immunoisolated from egg extracts with anti-Cdc27 antibodies and another that had been partially purified by ion-exchange chromatography. Furthermore, we utilized bacterially expressed His6-C dc27 as a substrate in these studies.

In the first set of experiments, we isolated the hypophosphorylated APC from interphase egg extracts with anti-Cdc27 antibodies (Fig. 5A ). Then, we incubated the immunoprecipitated APC with either a dimeric $\mathrm{Cdc} 2 /$ $\Delta$ cyclin B complex or a trimeric $\mathrm{p} 9 / \mathrm{Cdc} 2 / \Delta$ cyclin B complex in the presence of $\left[\gamma^{-32} \mathrm{P}\right] \mathrm{ATP}$. As assessed by silver staining, we determined that these two preparations contained equival ent amounts of $\mathrm{Cdc} 2$ and $\Delta$ cycl in $B$ (data not shown). As shown in Figure 5A (lane f), we observed that $\mathrm{p} 9 / \mathrm{Cdc} 2 / \Delta$ cyclin B elicited substantial phosphorylation of two polypeptides that correspond to the hyperphosphorylated forms of the Cdc27 and BIME proteins, as determined by immunoblotting with antiCdc27 and anti-BIME antibodies (data not shown). In contrast, the phosphorylation of $\mathrm{Cdc} 27$ and BIME was

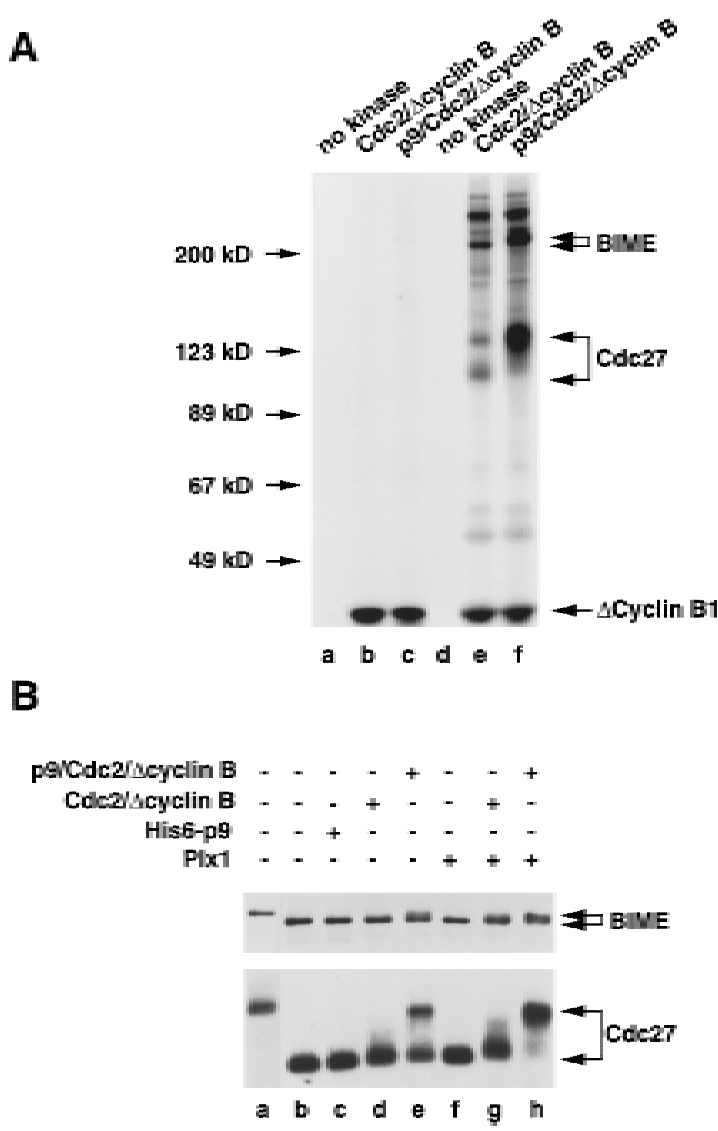

Figure 5. Phosphorylation of the $\mathrm{Cdc} 27$ and BIME subunits of the APC by recombinant $\mathrm{Cdc} 2 /$ cyclin B is strongly stimulated by p9. (A) The Xenopus APC was immunoprecipitated from interphase extracts with anti-Cdc27 antibodies bound to Affiprep protein A beads (lanes $d-f)$. In parallel, immunoprecipitations with control antibodies were also carried out (lanes a-c). The immunopreci pitates were washed as described in $M$ aterials and $M$ ethods. These washed immunoprecipitates were used as substrates for a Cdc2/ $\Delta$ cyclin B complex (lanes b,e) or a p9/ $\mathrm{Cdc} 2 / \Delta$ cyclin B complex (lanes $\mathrm{c}, \mathrm{f})$. Lanes a and d were used as controls in which kinase buffer $(5 \mathrm{~mm}$ Tris- $\mathrm{HCl}$ at $\mathrm{pH} 7.5,10$ $\mathrm{mm} \mathrm{MgCl}_{2}, 1 \mathrm{~mm}$ DTT, $0.1 \mathrm{mg} / \mathrm{ml}$ ovalbumin, $1 \mu \mathrm{M}$ okadaic acid, and $100 \mu \mathrm{M}$ ATP containing $5 \mu \mathrm{Ci}$ of [ $\gamma^{-32}$ P]ATP) only was added. Phosphorylation was analyzed by SDS-PAGE in a $8 \%$ polyacrylamide gel. (B) The interphase form of the Xenopus APC was partially purified from egg extracts by ion-exchange chromatography as described in Materials and Methods and used as a substrate for the $\mathrm{Cdc} 2 / \Delta$ cyclin B complex (lanes $d, g$ ), the p9/Cdc2/ $\Delta$ cyclin B complex (lane e,h), and PIxl (lane f-h). Following the kinase reactions, the samples were processed for immunoblotting with anti-Tsg24 antibodies (BIME; top) and anti-Cdc27 antibodies (bottom). Lane a depicts the partially purified APC from mitotic egg extracts; lane b shows a control containing a kinase buffer only; lane c contains no kinase but recombinant His6-p9 (10 ng/ $\mu \mathrm{l})$. 
much lower in the presence of a Cdc2/ $\Delta$ cyclin B complex lacking p9 (Fig. 5A, lane e). p9 does not appear to increase the intrinsic catalytic activity of the $C \mathrm{dc} 2 / \Delta c y-$ clin B complex in these assays because the autophosphorylation of $\Delta$ cyclin $B$ is similar in the presence and absence of p9 (Fig. 5A, cf. lanes e and f), and both complexes display similar histone $\mathrm{H} 1$ kinase activity (see Fig. 6).

In parallel experiments, we treated an APC fraction from interphase egg extracts that had been partially purified by ion-exchange chromatography with $\mathrm{Cdc} / \Delta \mathrm{cy}$ clin B or $\mathrm{p} 9 / \mathrm{Cdc} 2 / \Delta$ cyclin B (Fig. 5B). In addition, we incubated this fraction with the Xenopus Polo-like kinase $\mathrm{PIX1}$, either alone or in combination with $\mathrm{Cdc} 2 /$ $\Delta$ cyclin B or $\mathrm{p} 9 / \mathrm{Cdc} / \Delta$ cyclin B. To assess phosphorylation of the APC, we performed immunoblotting with anti-Cdc27 or anti-T sg24 (BIME) antibodies. In the case of Cdc27, we observed that $\mathrm{p} 9 / \mathrm{Cdc} 2 / \Delta \mathrm{cyclin} B$ elicited the appearance of hyperphosphorylated $\mathrm{Cdc} 27$ whereas Cdc2/ $\Delta$ cyclin B al one had little effect (Fig. 5B, bottom, cf. lanes $d$ and e). Active PIx 1 al one did not cause hyperphosphorylation of $\mathrm{Cdc} 27$ under these conditions. However, PIx1 appeared to enhance the phosphorylation of

\section{A}

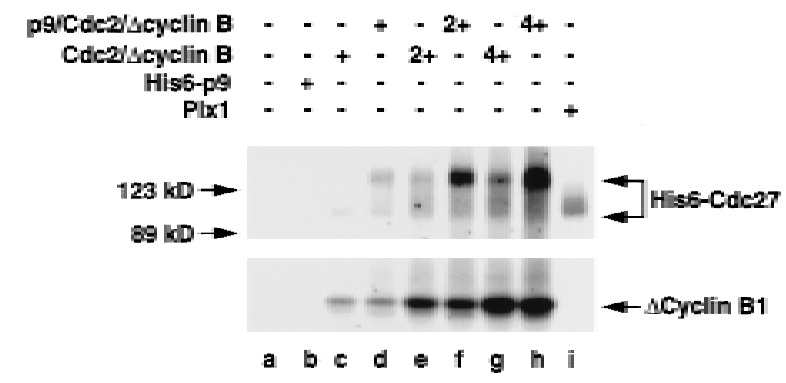

B

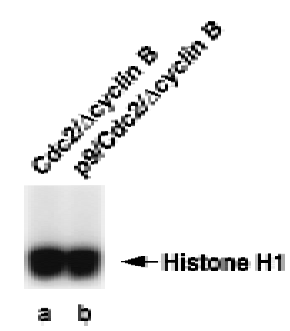

Figure 6. p9 strongly enhances the phosphorylation of the isolated, recombinant His6-Cdc27 protein by $\mathrm{Cdc} 2 / \Delta \mathrm{cyclin} \mathrm{B}$. (A) The human $\mathrm{Cdc} 27$ protein with a histidine-tag at its aminoterminal end (His6-Cdc27) was expressed in bacteria and tested as a substrate for the $C d c 2 / \Delta$ cyclin B complex (lanes c,e,g), the $\mathrm{p} 9 / \mathrm{Cdc} 2 / \Delta \mathrm{cyclin} \mathrm{B}$ complex (lanes d,f,h), and PIxl (lane i) in the presence of $\left[\gamma^{-32}\right.$ P]ATP. Lanes e and $f$ contain twice as much kinase as lanes $c$ and $d$, and lanes $g$ and $h$ contain four times more kinase. Lane a is control to which kinase buffer only has been added. Lane b contains no kinase but recombinant His6-p9

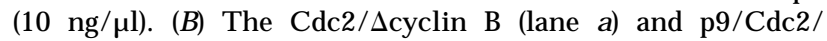
$\Delta$ cyclin B complexes (lane b) exhibit very similar histone $\mathrm{H} 1$ kinase activity.
Cdc27 in the presence of both $\mathrm{p} 9 / \mathrm{Cdc} 2 / \Delta \mathrm{cyclin} B$ and, to a lesser extent, Cdc2/ $\Delta$ cyclin B (Fig. 5B, lanes f-h). In the same samples, the BIME protein al so displayed a subtle but reproducible reduction in electrophoretic mobility when treated with $\mathrm{p} 9 / \mathrm{Cdc} / \Delta \mathrm{cyclin} B$ but not $\mathrm{Cdc} 2 /$ $\Delta$ cyclin B (Fig. 5B, top, lanes d, e).

To pursue these observations further, we utilized a bacterially expressed form of the human His6-Cdc27 protein as a substrate (Fig. 6). These experiments were aimed at addressing the issue of whether $p 9$ affects the phosphorylation of $\mathrm{Cdc} 27$ by $\mathrm{Cdc} 2 / \Delta \mathrm{cyclin} \mathrm{B}$ directly or acts indirectly through some other component in the APC preparations. We incubated His6-C dc27 with varying concentrations of either $\mathrm{Cdc} 2 / \Delta \mathrm{cycl}$ in $\mathrm{B}$ or $\mathrm{p} 9 / \mathrm{Cdc} 2 /$ $\Delta$ cyclin B in the presence of [ $\gamma^{-32}$ P]ATP. Consistent with the results described above, $\mathrm{p} 9$ strongly stimulated the phosphorylation of His6-Cdc27 by recombinant $\mathrm{Cdc} 2 /$ $\Delta$ cyclin B so that His6-C dc27 migrated at its hyperphosphorylated position in SDS gels (Fig. 6A, top, lanes C-h). Although PIX1 did phosphorylate His6-Cdc27, it did not elicit hyperphosphorylation of this substrate under these conditions (Fig. 6A, lane i). In strong contrast to His6Cdc27, the phosphorylation of $\Delta$ cyclin B was similar in the absence and presence of p9 (Fig. 6A, bottom, lanes c-h). Finally, both the Cdc2/ $\Delta$ cyclin B and p9/Cdc2/ $\Delta$ cyclin B complexes phosphorylated the general Cdk substrate histone $\mathrm{H} 1$ to si milar extents (Fig. 6B). Thus, it appears that p9 acts by facilitating the recognition of His6-Cdc27 by $\mathrm{Cdc} 2 / \Delta$ cyclin B rather than increasing the inherent catalytic activity of $\mathrm{Cdc} / \Delta \mathrm{cyclin} \mathrm{B}$.

\section{Discussion}

In this study we have analyzed the role of $\mathrm{p} 9$, a Xenopus homol og of the Cdk-associated Sucl/Cks protein, at mitosis in Xenopus egg extracts. As described previously, egg extracts that are induced to enter $M$ phase in the absence of $p 9$ are unable to carry out proteolysis of the mitotic B-type cyclins (Patra and Dunphy 1996). However, the molecular basis of this defect was not resolved previously. Similarly, fission yeast cells lacking the Sucl protein become arrested in $M$ phase by an unknown mechanism (M oreno et al. 1989; Basi and Draetta 1995). The proteolysis of cyclin B after entry into mitosis is achieved by the ubiquitin-dependent, APC-mediated proteasomal pathway (for review, see Ciechanover 1994; Murray 1995; King et al. 1996; Hoyt 1997). This pathway involves a series of concerted biochemical steps, one or more of which apparently requires the involvement of p9. Although the E1 and E2 components of this pathway are constitutively active throughout the cell cycle, the E3 component or ubiquitin ligase is activated only on entry into mitosis (King et al. 1995; Lahav-Baratz et al. 1995; Peters et al. 1996). The APC is essential for E3 activity, but other proteins such as those in the Cdc20 and Cdh1/Hctl family of proteins, may also be necessary, even though apparently they are not permanent constituents of the APC (Schwab et al. 1997; Visintin et al. 1997). Once cyclin B undergoes polyubiquitination, it is delivered to the proteasome, where it is subjected to 
rapid and processive proteolysis. Cdc2 remains stably bound to polyubiquitinated cyclin B (Amon et al. 1994; Brandeis and Hunt 1996; Y amano et al. 1996), but both Cdc2 and p9 are spared from destruction by the proteasome.

In principle, p9 could be required for ubiquitin-mediated degradation of cyclin B at any one of several steps. The activation of the APC at mitosis is known to be dependent on active Cdc2/cyclin B (Luca and Ruderman 1989; Félix et al. 1990b; Hershko et al. 1994; LahavBaratz et al. 1995; Sudakin et al. 1995). The mechanism by which $\mathrm{Cdc} 2$ /cyclin B triggers activation of the APC has been unresolved, but the critical target(s) of $\mathrm{Cdc} 2 /$ cyclin B in this pathway could require p9 for properly controlled phosphorylation. Another explanation would be that $\mathrm{Cdc} 2 /$ cyclin $\mathrm{B}$ cannot serve as a substrate for APC-dependent ubiquitin ligase activity when p9 is not associated with the Cdk complex. In this scenario, p9 would act as a specificity factor in targeting cyclin B for polyubiquitination by the active APC. Finally, another model would be that the complex of $\mathrm{Cdc} 2$ and polyubiquitinated cyclin B could not interact properly with the proteasome in the absence of $p 9$.

To distinguish among these possibilities, we depleted p9 from $M$-phase extracts in which the APC is already active. If p9 were requi red di rectly for the ubiquitination and/or proteolysis of cyclin B, then removal of $p 9$ at this time should abolish cyclin B destruction. Alternatively, if p9 plays a regulatory role in switching on or allowing the manifestation of ubiquitin-ligase (E3) activity, then the immunodepletion of $\mathrm{p} 9$ from extracts in which the cyclin destruction machinery has al ready been activated should not have any effect on cyclin B degradation. Our results indicate that $\mathrm{p} 9$ acts by control ling E3 activity, as depletion of $p 9$ from extracts al ready in $M$ phase has no effect on the ability of these extracts to degrade cycl in B. This observation is clearly not consistent with the notion that p9 is required directly for recognition of cyclin $B$ by either the E3-ubiquitin ligase or the proteasome. Instead, our results strongly suggest that activation of the APC cannot occur in the absence of p9.

To explore how p9 might affect regulation of the APC, we have examined the phosphorylation of the Cdc27 component of the APC in extracts that have been induced to enter mitosis in the absence of p9. N ormally, Cdc27 and a number of other subunits of the APC (e.g., APC 1-BIME) undergo phosphorylation at $M$ phase as the cyclin destruction machinery is switched on. Phosphorylation of the APC appears to be important for its activity at mitosis, because treatment of the APC with phosphatase abol ishes ubi quitin-ligase acti vity (King et al . 1995; Lahav-Baratz et al. 1995; Peters et al. 1996). Significantly, we find that the mitotic hyperphosphorylation of the $\mathrm{Cdc} 27$ protein is abolished in extracts that have entered $M$ phase in the absence of $p 9$. These same extracts are totally incapable of carrying out the destruction of cyclin B. Taken together, our results strongly support a model in which p9 is required for activation of the cycl in destruction machinery.

In an effort to investigate how p9 might be regulating the destruction machinery, we examined whether p9 could associate physically with components of the APC and/or direct phosphorylation of the APC by the C dc2/ cyclin B complex. We found that some p9 can be found in a complex with the $\mathrm{Cdc} 27$ component of the APC at mitosis, but not during interphase. Similar results have been obtained in the clam oocyte system (Sudakin et al. 1997). However, only a small proportion of the Cdc27 appears to be associated with $\mathrm{p} 9$ at $\mathrm{M}$ phase in Xenopus egg extracts, suggesting that this is a weak or transient interaction.

In another series of experiments, we investigated whether p9 could direct the phosphorylation of the APC by the $\mathrm{Cdc} 2$ /cyclin $\mathrm{B}$ complex. It is clear that activation of $\mathrm{Cdc} 2 /$ cyclin $\mathrm{B}$ at mitosis turns on the cyclin destruction machinery, but the molecular mechanism of this phenomenon has not been elucidated. The APC can be depl eted from Xenopus egg extracts by the M PM-2 antibody, which recognizes a phosphopeptide epitope on mitotic phosphoproteins (King et al. 1995). However, although Cdc2 can create the M PM-2 epitope on substrate proteins, other kinases such as PIX1, the Xenopus Pololike kinase, also clearly possess this capacity (Kuang and Ashorn 1993; Kumagai and Dunphy 1996). There is a decided lag between the appearance of active Cdc2/ cyclin B and the phosphorylation of Cdc27 and activation of the APC (Hershko et al. 1994; Lahav-Baratz et al. 1995; Sudakin et al. 1995). This observation might suggest that there is an intermediary step(s) or modulating event(s) between activation of $\mathrm{Cdc} 2 /$ cyclin $B$ and the APC. Consistent with this possibility, it has been reported that the murine Polo-like kinase (PIk) and Cdc2/ cyclin B can collaborate to activate the APC in vitro (Kotani et al. 1998). Kotani et al. observed that Cdc2/ cyclin B did not phosphorylate the APC directly but acted indirectly by activating PIk. However, it is not known whether $\mathrm{Cdc} 2 / \mathrm{cycl}$ in $\mathrm{B}$ is the physiological activator of Plk in vivo. Similarly, Descombes and Nigg (1998) have implicated PIx1 in the control of cyclin degradation in cytostatic factor (CSF)-arrested Xenopus egg extracts. Furthermore, proteins in the $\mathrm{Cdc} 20$ and $\mathrm{Cdh} 1 /$ Hct 1 family are essential for APC functions (Dawson et al. 1995; Sigrist et al. 1995; Schwab et al. 1997; Visintin et al. 1997; Shirayama et al. 1998). Collectively, these findings suggest that $\mathrm{Cdc} 2$ /cyclin $B$ is necessary but not sufficient for activation of the APC.

We find that recombinant $\mathrm{Cdc} 2 /$ cyclin $\mathrm{B}$ can bring about phosphorylation of APC components such as the Cdc27 and BIME proteins, but this reaction occurs efficiently only in the presence of $p 9$. This effect is most obvious in the case of the Cdc27 component of the APC, but the Cdc2-dependent phosphorylation of BIME is al so enhanced by $\mathrm{p} 9$. In the case of Cdc27, the p9-stimulated phosphorylation was observed with several distinct Cdc27-containing preparations. In particular, we utilized an APC fraction that had been partially purified by ionexchange chromatography, an APC preparation that had been immunopurified with anti-Cdc27 antibodies, and recombinant $\mathrm{His6}-\mathrm{Cdc} 27$ from bacteria. In all three cases, the presence of $\mathrm{p} 9$ in the $\mathrm{Cdc} 2 /$ cyclin B complex 
strongly stimulated the phosphorylation of Cdc27. Because this effect could be observed even with bacterially expressed His6-Cdc27, it appears that p9 directly enhances the ability of $\mathrm{Cdc} 2 /$ cyclin B to phosphorylate the $\mathrm{Cdc} 27$ protein. Although there is one report that the fission yeast Sucl protein can suppress the phosphorylation of intermediate filament proteins by $\mathrm{Cdc} 2$ (Kusubata et al. 1992), our studies represent the first example in which a Sucl/Cks protein can be shown to modulate the functional properties of a $\mathrm{Cdk}$ by promoting phosphorylation of a Cdk substrate. This observation rational izes why the Suc1/Cks protein is needed for cell cycle progression. As discussed above, the APC is most likely regulated by an additional kinase(s) besi des $\mathrm{Cdc} 2 /$ cyclin B in vivo. In the future, it will be important to assess the relative contributions of $\mathrm{Cdc} 2 / \mathrm{cyclin} \mathrm{B}$ and other kinases such as the Polo-like kinases under conditions where $\mathrm{Cdc} 2 / \mathrm{cyclin} \mathrm{B}$ contains an associated $\mathrm{p9}$ subunit. For example, Kotani et al . (1998) did not observe that baculovirus-expressed $\mathrm{Cdc} 2 /$ cyclin B could phosphorylate the APC, but this Cdk did not contain a recombinant Sucl/Cks protein.

The rational e for why $\mathrm{Cdc} 2 /$ cyclin B should require an accessory subunit to phosphorylate $\mathrm{Cdc} 27$ efficiently remains to be resolved. In structural studies, it has been found that the human $\mathrm{Cks}$ l protein contains a potential anion binding pocket that could interact with a phosphate group (Arvai et al. 1995; Bourne et al. 1996). Human Cksl is located on the same face of the C dk as the catalytic site. The orientation of the anion-binding pocket suggests that it would most likely bind to a phosphate moiety in a ligand that interacts with the Cdk/ cyclin complex (e.g., a substrate) rather than a phosphate in the Cdk/ cyclin complex itself. Interestingly, Cdc27 is multiply phosphorylated at mitosis, which raises the possibility that the extent of phosphorylation of $\mathrm{Cdc} 27$ could influence its recognition by $\mathrm{p} 9 / \mathrm{Cdc} / \mathrm{cyclin} \mathrm{B}$. In this scenario, p9/Cdc2/cycl in B would have a low affinity for unphosphorylated or hypophosphorylated Cdc27 and a higher affinity for more extensively phosphorylated Cdc27. In principle, this action of p9 as a docking factor might help to explain some characteristic features in the kinetics of cyclin B destruction, such as the requirement for a threshold concentration of $\mathrm{Cdc} / \mathrm{cycl}$ in $\mathrm{B}$ and the lag between the activation of $\mathrm{Cdc} 2 /$ cyclin B and the activation of the APC.

In conclusion, we have demonstrated that p9 directly regulates phosphorylation of the APC at mitosis. This observation should aid in unraveling the complex series of events that result in the metaphase-anaphase transition in eukaryotic cells. Moreover, it will be important to assess whether p9 controls the phosphorylation of Cdk substrates involved in other cell cycle processes.

\section{Materials and methods}

Preparation of recombinant, untagged Xe-p9 in Sf9 insect cells

To prepare a full-length recombinant p9 lacking a histidine tag, we subcloned the N del-EcoRI fragment of pVL1393N-His6-p9
(Patra and Dunphy 1996) into pVL1393 that had been digested with $\mathrm{Ndel}$ and EcoRI. The resulting vector was used for the production of untagged p9 in Sf9 insect cells (Kumagai and Dunphy 1995).

\section{Preparation of $\mathrm{Cdc} 2 /$ cyclin B complexes}

A Cdc2/ $\Delta$ cyclin B complex was prepared as described in Kumagai and Dunphy (1995). Because high concentrations of p9 inhibit activation of $\mathrm{Cdc} 2$ by the Cdk-activating kinase (D. Patra and W.G. Dunphy, unpubl.), a p9/Cdc2/ $\Delta$ cyclin B complex containing equimolar amounts of all three proteins was prepared as follows. N ickel-agarose beads containing $\Delta$ cyclin B $(25 \mu \mathrm{l})$ were incubated with $500 \mu \mathrm{l}$ of a Cdc2-containing Sf 9 cell lysate for 20 min at $22^{\circ} \mathrm{C}$ in the presence of $0.5 \mathrm{~mm} \mathrm{ATP}$ and $10 \mathrm{mM} \mathrm{M} \mathrm{gCl}$. The beads were washed three times with HEPES-buffered sal ine (HBS; $10 \mathrm{~mm}$ HEPES-KOH at pH 7.5, $150 \mathrm{~mm} \mathrm{NaCl}$ ) and then incubated with $500 \mu \mathrm{l}$ of a p9-containing Sf9 cell lysate at $4^{\circ} \mathrm{C}$ for $30 \mathrm{~min}$. The beads were isolated by centrifugation and then incubated further with a fresh $500-\mu \mathrm{l}$ aliquot of p9-containing lysate for $30 \mathrm{~min}$. The beads were then washed three times with HBS and eluted with $250 \mathrm{~mm}$ imidazole in HBS. The kinase complexes were then used at a final dilution of $1: 10$ in HBS ( 1 : 100 for assessing histone $\mathrm{H} 1$ kinase activity). Complexes between the Cdc2-AF mutant and either truncated $\Delta$ cyclin B1 or the full-length cyclin B1 were prepared by gel filtration chromatography with a SMART system (Pharmacia; Kumagai and Dunphy 1995).

\section{Preparation of Xenopus egg extracts}

CSF-arrested extracts from unactivated Xenopus eggs were prepared as described (Murray 1991). Activation of these egg extracts by the addition of $\mathrm{CaCl}_{2}(0.4 \mathrm{~mm})$ and visual monitoring of the assembly and disassembly of nuclei formed around sperm chromatin (500 demembranated Xenopus sperm nuclei per microliter of extract) were described previously (Kumagai and Dunphy 1995; Mueller et al. 1995a). In some cases, cycloheximide $(100 \mu \mathrm{g} / \mathrm{ml})$ was added as described in the legends to Figures $1-4$.

Processing of anti-Cdc27 immunoprecipitates for treatment with kinases

To immunoprecipitate the Xenopus APC from interphase extracts to investigate the phosphorylation of APC subunits by the $\mathrm{Cdc} 2 / \Delta$ cyclin B complex or the $\mathrm{p} 9 / \mathrm{Cdc} 2 / \Delta \mathrm{cyclin} \mathrm{B}$ complex, anti-Cdc27 antibodies (Tugendreich et al. 1995; King et al. 1995) were first bound to Affi-prep protein A support beads (Bio$\mathrm{Rad})$ at $4^{\circ} \mathrm{C}$ for an hour. After washing the beads with HBS, interphase extracts containing cycloheximide $(100 \mu \mathrm{g} / \mathrm{ml})$ were added, mixed thoroughly, and incubated at $4^{\circ} \mathrm{C}$ for $2 \mathrm{hr}$. The beads were then recovered by centrifugation and washed according to the protocol of King et al. (1995) with minor modifications. The beads were first washed six times with $20 \mathrm{~mm}$ Tris$\mathrm{HCl}\left(\mathrm{pH}\right.$ 7.7), $500 \mathrm{~mm} \mathrm{KCl}, 0.1 \mathrm{~mm} \mathrm{CaCl}_{2}, 1 \mathrm{~mm} \mathrm{MgCl}_{2}, 1 \mathrm{~mm}$ DTT, $0.5 \%$ N P-40 and then washed twice with $20 \mathrm{~mm}$ Tris- $\mathrm{HCl}$ (pH 7.7), $100 \mathrm{~mm} \mathrm{KCl}, 0.1 \mathrm{~mm} \mathrm{CaCl}_{2}, 1 \mathrm{~mm} \mathrm{MgCl}{ }_{2}, 1 \mathrm{~mm}$ DTT. Finally, the beads were washed twice with HBS.

Partial purification of the APC from Xenopus egg extracts

The Xenopus APC was prepared from high-speed supernatants of both CSF-arrested ( $M$ phase) and interphase egg extracts as described in King et al. (1995). Fractionations of the high-speed supernatants were performed with a 6-ml Source 15 Q column (Pharmacia) that was el uted with six column volumes of a linear 
salt gradient from 100 to $500 \mathrm{~mm} \mathrm{KCl}$ in buffer Q (20 mM Tris$\mathrm{HCl}$ at $\mathrm{pH} 7.7,0.1 \mathrm{~mm} \mathrm{CaCl} 2,1 \mathrm{~mm} \mathrm{MgCl}_{2}, 1 \mathrm{~mm} \mathrm{DTT}$ ). Fractions $(2.5 \mathrm{ml})$ were collected and analyzed by immunoblotting with anti-Cdc27 and anti-Tsg24 (BIME) antibodies. Fractions containing peak amounts of both the $\mathrm{Cdc} 27$ and BIME proteins were collected, desalted on PD10 columns (Pharmacia), and concentrated to $500 \mu \mathrm{l}$ by use of Centriprep-10 concentrators (A micon). The concentrated fractions were al iquoted and stored at $-70^{\circ} \mathrm{C}$.

\section{Preparation of recombinant His6-Cdc27 in bacteria}

To prepare a full-length recombinant human $\mathrm{Cdc} 27$ with a sixhistidine tag at its amino-terminal end (His6-Cdc27) in bacteria, a PCR product containing the entire CDN A of $\mathrm{Cdc} 27$ was first prepared with pSTU16 as the template (Tugendreich et al. 1993). In this construct, the initiating codon (ATG) was converted into an Ndel restriction site with the primers $5^{\prime}$ TGAGTCCACATATGACGGTGCTGCAGGAACCC-3' and 5'-CGGAATTCCCAGAAGTTAAAATTCATCACTTTCAGCTGC-3'. After digestion of the PCR product with $\mathrm{Ndel}$ and EcoRI, it was then subcloned into the bacterial expression vector pET 9-His6 (Shou and Dunphy 1996) that had been digested with $\mathrm{Ndel}$ and EcoRI. The His6-Cdc27 protein was expressed in BL21(DE3)pLysS cells and purified by nickel agarose chromatography.

\section{Miscellaneous}

Preparation of recombinant His6-p9 in Sf9 insect cells, preparation of antibodies against a carboxy-terminal peptide of $\mathrm{p9}$, and depletion of $\mathrm{p} 9$ from $\mathrm{M}$-phase and interphase egg extracts with these anti-p9 antibodies bound to protein A-Sepharose beads (Sigma) were performed as reported previously (Patra and Dunphy 1996). Antibodies against the human cyclin B1 were obtained from U pstate Biotechnology (Lake Placid, NY). Antibodies against Xenopus Cdc25, Weel, and Myt1 were described previously (Kumagai and Dunphy 1992; Mueller et al. 1995a,b). Antibodies against human $\mathrm{Cdc} 27$ were generously supplied by Dr. P. Hieter (University of British Columbia, Vancouver, B.C., Canada), and antibodies against the mouse Tsg24 (BIM E; Starborg et al. 1994) were kindly provided by Dr. C. Hoog (Karolinska Institutet, Stockholm, Sweden). Immunobl otting with various antibodies was done as described (Coleman et al. 1993) by use of ${ }^{125} \mathrm{I}$-labeled protein A (ICN, Cleveland, OH) or ${ }^{125} \mathrm{I}-\mathrm{Ia}-$ beled sheep anti-mouse IgG antibodies (Amersham, Arlington Heights, IL). Detection of p9 in Figure $4 B$ and the $C d c 27$ and BIME proteins in Figure 5B was performed by chemiluminescence (ECL, Amersham) with a goat anti-rabbit-IgG-HRP conjugate (Bio-Rad). Coimmunoprecipitation of $\mathrm{Cdc} 27$ with p9 from egg extracts was performed with $100 \mu \mathrm{g} / \mathrm{ml}$ of anti-p9 antibodies as described (M ueller et al. 1995a; Patra and Dunphy 1996). Coimmunoprecipitation of p9 with Cdc27 from egg extracts was performed by use of a rabbit polycl onal antiserum (10 $\mu \mathrm{l}$ of serum per $100 \mu \mathrm{l}$ of egg extract) directed against the human Cdc27 protein (King et al. 1995; Tugendreich et al. 1995). Purification of active PIx1 from Sf9 cells treated with okadaic acid was performed as described previously (Kumagai and Dunphy 1996). Protein concentrations were determined by use of a BioRad protein assay kit with bovine serum albumin or lysozyme as the standard.

\section{Acknowledgments}

We thank our colleagues for comments on the manuscript. We are grateful to Philip Hieter for the human Cdc27 cDN A clone and for antibodies against the human $\mathrm{Cdc} 27$ protein, and to Christer Hoog for antibodies against the mouse Tsg24 protein (BIM E). D.P. wishes to thank Sophie Wang for Xenopus PIX1 and $M$ ary Kennedy and her laboratory members for the use of the FPLC (Pharmacia) system. D.P. has been supported by fellowships from the Leukemia Society of America and the American Cancer Society (California Division, Inc.). This work was supported by the Howard Hughes Medical Institute, in which W.G.D. is an investigator.

The publication costs of this article were defrayed in part by payment of page charges. This article must therefore be hereby marked "advertisement" in accordance with 18 USC section 1734 solely to indicate this fact.

\section{References}

Amon, A., S. Irniger, and K. N asmyth. 1994. Closing the cell cycle circle in yeast: $\mathrm{G} 2$ cyclin proteolysis initiated at mitosis persists until the activation of $\mathrm{Gl}$ cyclins in the next cycle. Cell 77: 1037-1050.

Arvai, A.S., Y. Bourne, M.J. Hickey, and J.A. Tainer. 1995. Crystal structure of the human cell cycle protein CksHsl: Single domain fold with similarity to kinase $\mathrm{N}$-lobe domain. J. Mol. Biol. 249: 835-842.

Basi, G. and G. Draetta. 1995. p13 ${ }^{\text {suc1 }}$ of Schizosaccharomyces pombe regulates two distinct forms of the mitotic cdc2 kinase. Mol. Cell. Biol. 15: 2028-2036.

Bourne, Y., M.H. Watson, M.J. Hickey, W. Holmes, W. Rocque, S.I. Reed, and J.A. Tainer. 1996. Crystal structure and mutational analysis of the human Cdk2 kinase complex with cell cycle-regulatory protein CksHsl. Cell 84: 863-874.

Brandeis, M. and T. Hunt. 1996. The proteolysis of mitotic cyclins in mammalian cells persists from the end of mitosis until the onset of S phase. EMBO J. 15: 5280-5289.

Brizuela, L., G. Draetta, and D. Beach. 1987. p13 ${ }^{\text {suc1 }}$ acts in the fission yeast cell division cycle as a component of the p34 ${ }^{\text {cdc2 }}$ protein kinase. EMBO J. 6: 3507-3514.

Ciechanover, A. 1994. The ubiquitin-proteasome proteolytic pathway. Cell 79: 13-21.

Cohen-Fix, O., J.-M. Peters, M.W. Kirschner, and D. Koshland. 1996. Anaphase initiation in Saccharomyces cerevisiae is controlled by the APC-dependent degradation of the anaphase inhibitor Pds1p. Genes \& Dev. 10: 3081-3093.

Coleman, T.R. and W.G. Dunphy. 1994. Cdc2 regulatory factors. Curr. Opin. Cell Biol. 6: 877-882.

Coleman, T.R., Z. Tang, and W.G. Dunphy. 1993. Negative regulation of the Weel protein kinase by direct action of the $\mathrm{Nim1/Cdr1} \mathrm{mitotic} \mathrm{inducer.} \mathrm{Cell} \mathrm{72:} \mathrm{919-929.}$

Dawson, I.A., S. Roth, and S. Artavanis-T sakonas. 1995. The Drosophila cell cycle gene fizzy is required for normal degradation of cyclins $A$ and $B$ during mitosis and has homology to the CDC20 gene of Saccharomyces cerevisiae. J. Cell Biol. 129: $725-737$.

Descombes, P. and E.A. N igg. 1998. The polo-like kinase PIX1 is required for $\mathrm{M}$-phase exit and destruction of mitotic regulators in Xenopus egg extracts. EMBO J. 17: 1328-1335.

Dunphy, W.G. and A. Kumagai. 1991. The Cdc25 protein contains an intrinsic phosphatase activity. Cell 67: 189-196.

Dunphy, W.G., L. Brizuela, D. Beach, and J. N ewport. 1988. The Xenopus cdc2 protein is a component of M PF, a cytoplasmic regulator of mitosis. Cell 54: 423-431.

Félix, M .A., P. Cohen, and E. Karsenti. 1990a. Cdc2 H1 kinase is negatively regulated by a type $2 \mathrm{~A}$ phosphatase in the Xenopus early embryonic cell cycle: Evidence from the effects of okadaic acid. EMBO J. 9: 675-683.

Félix, M.A., J.C. Labbé, M. Dorée, T. Hunt, and E. Karsenti. 
1990b. Triggering of cyclin degradation in interphase extracts of amphibian eggs by cdc2 kinase. Nature 346: 379382.

Funabiki, H., H. Yamano, K. Kumada, K. Nagao, T. Hunt, and M. Yanagi da. 1996. Cut2 proteolysis required for sister-chromatid separation in fission yeast. Nature 381: 438-441.

Gautier, J., C. N orbury, M. Lohka, P. N urse, and J. M aller. 1988. Purified maturation promoting factor contains the product of a Xenopus homolog of the fission yeast cell cycle control gene cdc2 ${ }^{+}$. Cell 54: 433-439.

Gautier, J., J. M inshull, M. Lohka, M. Glotzer, T. Hunt, and J.L. Maller. 1990. Cyclin is a component of maturation-promoting factor from Xenopus. Cell 60: 487-494.

Gautier, J., M.J. Solomon, R.N. Booher, J.F. Bazan, and M.W. Kirschner. 1991. Cdc25 is a specific tyrosine phosphatase that directly activates p34 cdc2. Cell 67: 197-211.

Glotzer, M., A.W. Murray, and M.W. Kirschner. 1991. Cyclin is degraded by the ubiquitin pathway. Nature 349: 132-138.

Hadwiger, J.A., C. Wittenberg, M.D. M endenhall, and S.I. Reed. 1989. The Saccharomyces cerevisiae CKS1 gene, a homolog of the Schizosaccharomyces pombe sucl ${ }^{+}$gene, encodes a subunit of the Cdc28 protein kinase complex. Mol. Cell. Biol. 9: 2034-2041.

Hayles, J., D. Beach, B. Durkacz, and P. N urse. 1986a. The fission yeast cell cycle control gene cdc2: Isolation of a sequence suc1 that suppresses cdc2 mutant function. Mol. Gen. Genet. 202: 291-293.

Hayles, J., S. Aves, and P. N urse. 1986b. sucl is an essential gene involved in both the cell cycle and growth in fission yeast. EMBO J. 5: 3373-3379.

Hershko, A., D. Ganoth, V. Sudakin, A. Dahan, L.H. Cohen, F.C. Luca, J.V. Ruderman, and E. Eytan. 1994. Components of a system that ligates cyclin to ubiquitin and their regulation by the protein kinase cdc2. J. Biol. Chem. 269: 49404946.

Hindley, J., G. Phear, M. Stein, and D. Beach. 1987. Suc1 $1^{+}$encodes a predicted 13-kilodalton protein that is essential for cell viability and is directly involved in the division cycle of Schizosaccharomyces pombe. Mol. Cell. Biol. 7: 504511.

Hoyt, M.A. 1997. Eliminating all obstacles: Regulated proteolysis in the eukaryotic cell cycle. Cell 91: 149-151.

Irniger S., S. Piatti, C. Michaelis, and K. N asmyth. 1995. Genes involved in sister chromatid separation are needed for B-type cyclin proteolysis in budding yeast. Cell 81: 269-277.

Izumi, T., D.H. Walker, and J.L. Maller. 1992. Periodic changes in phosphorylation of the Xenopus $\mathrm{C}$ dc25 phosphatase regulate its activity. Mol. Biol. Cell 3: 927-939.

Jessus, C., H. Rime, O. Haccard, J. Van Lint, J. Goris, W. Merlevede, and R. Ozon. 1991. Tyrosine phosphorylation of p34 ${ }^{\mathrm{cdc}}$ and $\mathrm{p} 42$ during meiotic maturation of Xenopus oocyte: Antagonistic action of okadaic acid and 6-DMAP. Development 111: 813-820.

Juang Y.-L., J. Huang, J.-M. Peters, M.E. M cLaughlin, C.-Y. Tai, and D. Pellman. 1997. APC-mediated proteolysis of Asel and the morphogenesis of the mitotic spindle. Science 275: 1311-1314.

King, R.W., P.K. Jackson, and M.W. Kirschner. 1994. Mitosis in transition. Cell 79: 563-571.

King, R.W., J.-M . Peters, S. Tugendreich, M . Rolfe, P. Hieter, and M.W. Kirschner. 1995. A 20 S complex containing CDC27 and CDC16 catalyzes the mitosis-specific conjugation of ubiquitin to cyclin B. Cell 81: 279-288.

King, R.W., R.J. Deshaies, J.-M. Peters, and M.W. Kirschner. 1996. How proteolysis drives the cell cycle. Science 274: 1652-1659.
Kotani, S., S. Tugendreich, M. Fujii, P.-M . Jorgensen, N. Watanabe, C. Hoog, P. Hieter, and K. Todokoro. 1998. PKA and MPF-activated polo-like kinase regulate anaphase-promoting complex activity and mitosis progression. Mol. Cell 1: $371-380$.

Kramer, K.M., D. Fesquet, A.L. Johnson, and L.H. Johnston. 1998. Budding yeast RSI1/APC2, a novel gene necessary for initiation of anaphase, encodes an APC subunit. EMBO J. 17: 498-506.

Kuang, J. and C.L. Ashorn. 1993. At least two kinases phosphorylate the M PM-2 epitope during Xenopus oocyte maturation. J. Cell Biol. 123: 859-868.

Kumagai, A. and W.G. Dunphy. 1992. Regulation of the cdc25 protein during the cell cycle in Xenopus extracts. Cell 70: 139-151.

- - . 1995. Control of the C dc2/cyclin B complex in Xenopus egg extracts arrested at a G2/M checkpoint with DNA synthesis inhibitors. Mol. Biol. Cell 6: 199-213.

- - - 1996. Purification and molecular cloning of Plx1, a Cdc25-regulatory kinase from Xenopus egg extracts. Science 273: 1377-1380.

Kusubata, M., T. Tokui, Y. Matsuoka, E. Okumura, K. Tachibana, S. Hisanaga, T. Kishimoto, H. Yasuda, M. Kamijo, Y. Ohba, K. Tsujimura, R. Yatani, and M. Inagaki. 1992. p13 ${ }^{\text {sucl }}$ suppresses the catalytic function of $p 34^{\text {cdc2 }}$ for intermediate filament proteins, in vitro. J. Biol. Chem. 267: 20937-20942.

Lahav-Baratz, S., V. Sudakin, J. Ruderman, and A. Hershko. 1995. Reversible phosphorylation controls the activity of cyclosome-associated cyclin-ubiquitin ligase. Proc. Natl. Acad. Sci. 92: 9303-9307.

Lamb, J.R., W.A. Michaud, R.S. Sikorski, and P.A. Hieter. 1994. Cdc16p, Cdc23p and Cdc27p form a complex essential for mitosis. EMBO J. 13: 4321-4328.

Liu, F., J.J. Stanton, Z. Wu, and H. Piwnica-Worms. 1997. The human Myt1 kinase preferentially phosphorylates cdc2 on threonine 14 and local izes to the endoplasmic reticulum and golgi complex. Mol. Cell. Biol. 17: 571-583.

Luca, F.C., and J.V. Ruderman. 1989. Control of programmed cyclin destruction in a cell-free system. J. Cell Biol. 109: 1895-1909.

Luca, F.C., E.K. Shibuya, C.E. Dohrmann, and J.V. Ruderman. 1991. Both cyclin A $\Delta 60$ and $B \Delta 97$ are stable and arrest cells in $M$-phase, but only cyclin B $\Delta 97$ turns on cyclin destruction. EMBO J. 10: 4311-4320.

McGowan, C.H. and P. Russell. 1993. Human Weel kinase inhibits cell-division by phosphorylating p34 ${ }^{\text {cdc2 }}$ exclusively on tyr15. EMBO J. 12: 75-85.

Milarski, K.L., W.G. Dunphy, P. Russell, S.J. Gould, and J.W. N ewport. 1991. Cloning and characterization of Xenopus Cdc2, a component of MPF. Cold Spring Harbor Symp. Quant. Biol. 56: 377-384.

Moreno, S., J. Hayles, and P. N urse. 1989. Regulation of p34 ${ }^{\text {cdc2 }}$ protein kinase during mitosis. Cell 58: 361-372.

Morgan, D.O. 1997. Cyclin-dependent kinases-engines, clocks and microprocessors. Annu. Rev. Cell Dev. Biol. 13: 261291.

Mueller, P.R., T.R. Coleman, and W.G. Dunphy. 1995a. Cell cycle regulation of a Xenopus Weel-like kinase. Mol. Biol. Cell 6: 119-134.

Mueller, P.R., T.R. Coleman, A. Kumagai, and W.G. Dunphy. 1995b. M yt1: A membrane-associated inhibitory kinase that phosphorylates cdc2 on both threonine-14 and tyrosine-15. Science 270: 86-90.

Murray, A. 1995. Cyclin ubiquitination: The destructive end of mitosis. Cell 81: 149-152. 
Murray, A.W. 1991. Cell-cycle extracts. Methods Cell Biol. 36: 581-605.

Murray, A.W. and M.W. Kirschner. 1989. Cyclin synthesis drives the early embryonic cell cycle. Nature 339: 275-280.

Murray, A.W., M.J. Solomon, and M.W. Kirschner. 1989. The role of cyclin synthesis and degradation in the control of maturation promoting factor activity. Nature 339: 280-286.

Parker, L.L. and H. Piwnica-Worms. 1992. Inactivation of the p34 ${ }^{\text {cdc2 }}$-cyclin-B complex by the human Weel tyrosine kinase. Science 257: 1955-1957.

Patra, D. and W.G. Dunphy. 1996. Xe-p9, a Xenopus Sucl/Cks homolog, has multiple essential roles in cell cycle control. Genes \& Dev. 10: 1503-1515.

Peters, J.-M., R.W. King, C. Hoog, and M.W. Kirschner. 1996. Identification of BIME as a subunit of the anaphase-promoting complex. Science 274: 1199-1201.

Picard, A., J.C. Labbé, H. Barakat, J.C. Cavadore, and M . Dorée. 1991. Okadaic acid mimics a nucl ear component required for cyclin B-C dc2 kinase microinjection to drivestarfish oocytes into M-phase. J. Cell Biol. 115: 337-344.

Richardson, H.E., C.S. Stueland, J. Thomas, P. Russell, and S.I. Reed. 1990. Human cDN As encoding homologs of the small p34 cdc28/cdc2-associated protein of Saccharomyces cerevisiae and Schizosaccharomyces pombe. Genes \& Dev. 4: 13321344.

Schwab, M., A.S. Lutum, and W. Seufert. 1997. Yeast Hct1 is a regulator of Clb2 cyclin proteolysis. Cell 90: 683-693.

Shirayama, M., W. Zachariae, R. Ciosk, and K. N asmyth. 1998. The polo-like kinase Cdc5p and the WD-repeat protein Cdc20/Fizzy are regulators and substrates of the anaphase promoting complex in Saccharomyces cerevisiae. EMBO J. 17: 1336-1349.

Shou, W. and W.G. Dunphy. 1996. Cell cycle control by Xenopus p28 ${ }^{\mathrm{Ki} \times 1}$, a devel opmentally regulated inhibitor of cyclindependent kinases. Mol. Biol. Cell 7: 457-469.

Sigrist, S.J., H. Jacobs, R. Stratmann, and C.F. Lehner. 1995. Exit from mitosis is regulated by Drosophila fizzy and the sequential destruction of cyclins $A, B$ and B3. EMBO J. 14: 4827-4838.

Starborg, M., E. Brundell, K. Gell, and C. Hoog. 1994. A novel murine gene encoding a $216-k D$ a protein is related to a mitotic checkpoint regulator previously identified in AspergilIus nidulans. J. Biol. Chem. 269: 24133-24137.

Solomon, M.J., T. Lee, and M.W. Kirschner. 1992. Role of phosphorylation in p34cdc2 activation: Identification of an activating kinase. Mol. Biol. Cell 3: 13-27.

Sudakin, V., D. Ganoth, A. Dahan, H. Heller, J. Hershko, F.C. Luca, J.V. Ruderman, and A. Hershko. 1995. The cyclosome, a large complex containing cyclin-sel ective ubiquitin ligase activity, targets cyclins for destruction at the end of mitosis. Mol. Biol. Cell 6: 185-197.

Sudakin, V., M. Shteinberg, D. Ganoth, J. Hershko, and A. Hershko. 1997. Binding of activated cyclosome to p13 ${ }^{\text {suc1 }}$. J. Biol. Chem. 272: 18051-18059.

Tang, Y. and S.I. Reed. 1993. The Cdk-associated protein Cks1 functions both in $G_{1}$ and $G_{2}$ in Saccharomyces cerevisiae. Genes \& Dev. 7: 822-832.

Tugendreich, S., M.S. Boguski, M.S. Seldin, and P. Hieter. 1993. Linking yeast genetics to mammalian genomes: Identification and mapping of the human homolog of $\mathrm{Cdc} 27$ via the expressed sequence tag (EST) data base. Proc. Natl. Acad. Sci. 90: 10031-10035.

Tugendreich, S., J. Tomkiel, W. Earnshaw, and P. Hieter. 1995. $\mathrm{CDC} 27 \mathrm{Hs}$ colocalizes with $\mathrm{CDC} 16 \mathrm{Hs}$ to the centrosome and mitotic spindle and is essential for the metaphase to anaphase transition. Cell 81: 261-268.
Visintin, R., S. Prinz, and A. Amon. 1997. CDC20 and CDH1: A family of substrate-specific activators of APC-dependent proteolysis. Science 278: 460-463.

Watanabe, N., M. Broome, and T. Hunter. 1995. Regulation of the human Weelhu CDK tyrosine 15-kinase during the cell cycle. EMBO J. 14: 1878-1891.

Yamada, H., K. Kumada, and M. Yanagida. 1997. Distinct subunit functions and cell cycle regulated phosphorylation of 20S APC / cycl osome required for anaphase in fission yeast. J. Cell Sci. 110: 1793-1804.

Yamano, H., J. Gannon, and T. Hunt. 1996. The role of proteolysis in cell cycle progression in Schizosaccharomyces pombe. EMBO J. 15: 5268-5279.

Yamashita, Y.M., Y. Nakaseko, I. Samejima, K. Kumada, H. Yamada, D. Michael son, and M. Yanagida. 1996. 20 S cyclosome complex formation and proteolytic activity inhibited by the CAM P/PKA pathway. Nature 384: 276-279.

Yu, H., J.-M. Peters, R.W. King, A.M. Page, P. Hieter, and M.W. Kirschner. 1998. Identification of a cullin homology region in a subunit of the anaphase-promoting complex. Science 279: 1219-1222.

Zachariae, W., T.H. Shin, M. Galova, B. Obermaier, and K. N asmyth. 1996. Identification of subunits of the anaphase-promoting complex of Saccharomyces cerevisiae. Science 274: 1201-1204.

Zachariae, W., A. Shevchenko, P.D. Andrews, R. Ciosk, M. Galova, M.J.R. Stark, M. Mann, and K. N asmyth. 1998. Mass spectrometric analysis of the anaphase-promoting complex from yeast: Identification of a subunit related to cullins. Science 279: 1216-1219. 


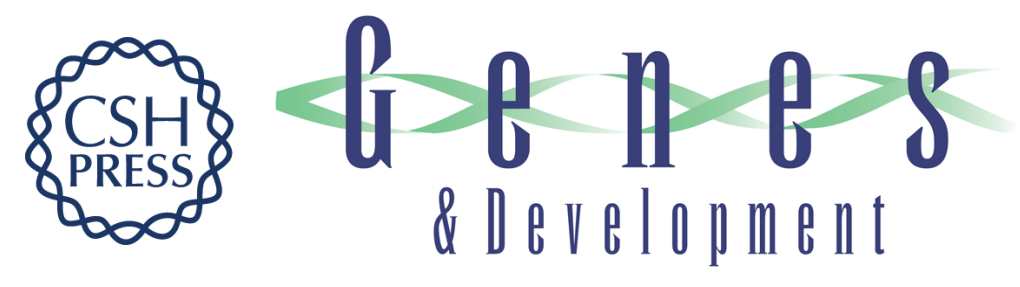

\section{Xe-p9, a Xenopus Suc1/Cks protein, is essential for the Cdc2-dependent phosphorylation of the anaphase- promoting complex at mitosis}

Debabrata Patra and William G. Dunphy

Genes Dev. 1998, 12:

Access the most recent version at doi:10.1101/gad.12.16.2549

References This article cites 80 articles, 40 of which can be accessed free at: http://genesdev.cshlp.org/content/12/16/2549.full.html\#ref-list-1

License

Email Alerting Receive free email alerts when new articles cite this article - sign up in the box at the top Service right corner of the article or click here.

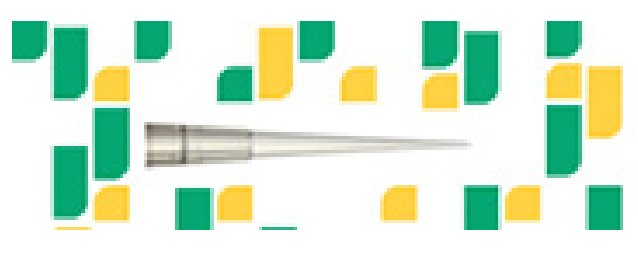

Focused on your science. 